\title{
The $\mathrm{C}_{4}$-Pathway of Photosynthesis \\ EVIDENCE FOR AN INTERMEDIATE POOL OF CARBON DIOXIDE AND THE IDENTITY OF THE DONOR $\mathrm{C}_{4}$-DICARBOXYLIC ACID
}

\author{
BY M. D. HATCH \\ Division of Plant Industry, Commonwealth Scientific and Industrial Research Organization, \\ P.O. Box 109, Canberra City, A.C.T. 2601, Australia
}

(Received 21 June 1971)

\begin{abstract}
1. Leaves were exposed to ${ }^{14} \mathrm{CO}_{2}$ under steady-state conditions for photosynthesis. The kinetics of entry or loss of label in pools of $\mathrm{CO}_{2}$ and other compounds was examined during the period of the pulse and a 'chase' with ${ }^{12} \mathrm{CO}_{2}$. 2. With maize the kinetics of labelling of the major $\mathrm{CO}_{2}$ pool and of depletion of label during a 'chase' was consistent with this pool being derived from the C-4 of malate and being the precursor of the C-1 of 3-phosphoglycerate. 3. Similar results were obtained for Amaranthus leaves except that the C-4 of aspartate rather than malate was apparently the primary source of $\mathrm{CO}_{2} .4$. The size and turnover time of the $\mathrm{CO}_{2}$ and $\mathrm{C}_{4}$ acid pools was calculated. These results provided the basis for estimating the concentration of $\mathrm{CO}_{2}$ in the bundle-sheath cells or chloroplasts assuming the pool was largely restricted to one or other of these compartments. 5. These findings are considered in relation to current schemes for the $\mathrm{C}_{4}$-pathway and the operation of a $\mathrm{CO}_{2}$ concentrating mechanism to serve ribulose diphosphate carboxylase.
\end{abstract}

The view is now widely held (see Hatch, Osmond \& Slatyer, 1971) that during the operation of the $\mathrm{C}_{4}$-pathway, $\mathrm{C}_{4}$-dicarboxylic acids are formed in the mesophyll chloroplasts and then transferred to the bundle-sheath cells where the C.4 is released as $\mathrm{CO}_{2}$ and refixed by ribulose diphosphate carboxylase. This proposition, one of two previously considered (Hatch \& Slack, 1966, 1970a), has been supported by studies on the activity and location of enzymes. It is now known that $\mathrm{C}_{4}$-pathway species contain sufficient ribulose diphosphate carboxylase to account for its operation as an integral reaction of the photosynthetic process (Bjorkman \& Gauhl, 1969; Andrews \& Hatch, 1971). One group of $\mathbf{C}_{4}$-pathway species contain high activities of 'malic' enzyme (Slack \& Hatch, 1967; Downton, 1970; Hatch \& Slack, 1970a; Andrews, Johnson, Slack \& Hatch, 1971; Chen, Brown \& Black, 1971) and this is located in the bundle-sheath chloroplasts together with ribulose diphosphate carboxylase (Slack, Hatch \& Goodchild, 1969). In these species NADP-malate dehydrogenase and probably phosphoenolpyruvate carboxylase are located in the mesophyll chloroplasts (Slack et al. 1969). Other studies have provided similar information, at least about the intercellular distribution of these enzymes (Bjorkman \& Gauhl, 1969; Berry, Downton \& Tregunna, 1970; Edwards, Le日, Chen \& Black,
1970 ; Edwards \& Black, 1971). Thus, this particular group of species contains enzymes with sufficient activity that are also in a location suitable for supporting a mechanism of the type proposed above, involving transport and decarboxylation of malate (Andrews et al. 1971). However, several other $\mathbf{C}_{4}$-pathway species contain little 'malic' enzyme (Hatch \& Slack, 1970a; Downton, 1970; Andrews et al. 1971; Chen et al. 1971) and also less NADP-malate dehydrogenase (Andrews et al. 1971). These deficiencies are compensated for by much higher alanine and aspartate aminotransferase activities (Andrews et al. 1971) and it was concluded that aspartate may replace malate as the donor of $\mathrm{CO}_{2}$ in these species. Recent studies of $\mathrm{CO}_{2}$ fixation by isolated mesophyll and bundlesheath cells have provided support for many of these concepts (Edwards et al. 1970; Edwards \& Black, 1971). An additional concept is that the reactions unique to the $\mathrm{C}_{4}$-pathway constitute a mechanism for concentrating $\mathrm{CO}_{2}$ for fixation by ribulose diphosphate carboxylase (Andrews et al. 1971; Hatch, 1971).

In the present studies direct evidence for the existence of an intermediate pool of $\mathrm{CO}_{2}$ in $\mathrm{C}_{4}$ pathway species and evidence establishing the identity of its precursor was looked for. By using radiotracers it was possible to detect substantial 
pools of $\mathrm{CO}_{2}$ in both maize and Amaranthus leaves. The kinetic characteristics of this pool were consistent with the primary source being the C-4 of malate in maize and the C-4 of aspartate in Amaranthus.

\section{MATERIALS}

Fully expanded leaves were obtained from maize (Zea mays, var. DS606A) or Amaranthus palmeri plants grown in soil in a greenhouse with the temperature controlled between 22 and $30^{\circ} \mathrm{C}$. $\mathrm{Ba}^{14} \mathrm{CO}_{3}(61 \mathrm{mCi} / \mathrm{mmol})$, [ $\left[\mathrm{U}^{14} \mathrm{C}\right]$ malate and $\left[\mathrm{U}-{ }^{14} \mathrm{C}\right]$ aspartate were obtained from The Radiochemical Centre, Amersham, Bucks., U.K., and $\left[4^{-14} \mathrm{C}\right]$ aspartate and malate dehydrogenase from Calbiochem, Los Angeles, Calif., U.S.A. $\left[4^{-14} \mathrm{C}\right]$ Malate was prepared from $\mathrm{NaH}^{14} \mathrm{CO}_{3}$ plus phosphoenolpyruvate in a system containing phosphoenolpyruvate carboxylase (Hatch \& Slack, 1968), NADH and malate dehydrogenase. 'Malic' enzyme was prepared from maize leaves by fractionation with $\left(\mathrm{NH}_{4}\right)_{2} \mathrm{SO}_{4}$ and gel chromatography on Sephadex G-200 as described by Johnson \& Hatch (1970). The fraction from Sephadex G-200 was adsorbed on to a Hypatite $\mathrm{C}$ column (Clarkson Chemical Co., Williamsport, Pa., U.S.A.) and then eluted with potassium phosphate buffer, $\mathrm{pH}$ 7.5.

\section{METHODS}

Treatment of leaves with ${ }^{14} \mathrm{CO}_{2}$ and isolation and identification of radioactive compounds. Maize leaf segments were allowed to establish a steady rate of photosynthesis in a 3-litre Perspex chamber as described by Hatch \& Slack (1966). The light-intensity was approx. $8000 \mathrm{ft}$ candles, measured as described by Hatch \& Slack (1966). Experiments were commenced by providing $0.5 \mathrm{mCi}$ $(8 \mu \mathrm{mol})$ of ${ }^{14} \mathrm{CO}_{2}$ in $2.5 \mathrm{ml}$ of air. For pulse-'chase' studies leaves were transferred to a second chamber that was flushed with humidified air after a period of $35 \mathrm{~s}$ in ${ }^{14} \mathrm{CO}_{2}$. Similar procedures were employed for $A$ maranthus leaves except that the petiole was allowed to protrude through the rubber gasket. Lateral portions of the lamina were removed so that the leaf width was approx. $2.5 \mathrm{~cm}$. A wad of tissue paper wrapped around the top of the petiole was kept saturated with water.

At the times specified individual leaves were removed from the chamber, kept in the dark in a stream of air for 2-3s and then killed by plunging them into tubes containing $30 \mathrm{ml}$ of $85 \%(w / v)$ ethanol containing 2,4-dinitrophenylhydrazine-HCl kept at $-80^{\circ} \mathrm{C}$ (Hatch \& Slack, 1966). The transient period in the dark was introduced to allow removal of the ${ }^{14} \mathrm{CO}_{2}$ associated with the boundary air layer and intercellular spaces. There are insignificant changes in the distribution of fixed label during such a period in the dark (Hatch \& Slack, 1966, 1970a). With this killing procedure oxaloacetate forms a stable hydrazone derivative, whereas free oxaloacetate would degrade to release C-4 as ${ }^{14} \mathrm{CO}_{2}$.

To retain the $\mathrm{CO}_{2}$ located in the leaves the tubes were quickly sealed with a stopper fitted with closed inlet and outlet connexions. The inlet extended to the bottom of the tubes. The sealed tubes were kept at $-20^{\circ} \mathrm{C}$ for $24 \mathrm{~h}$ to allow complete penetration of the killing mixture. The outlet tube was then connected to an evacuated $500-\mathrm{ml}$ flask containing $40 \mathrm{ml}$ of $0.1 \mathrm{~m}$-Hyamine hydroxide in a dioxane-toluene-ethanol mixture identical in proportion with the mixture used for subsequent scintillation counting. The connexion between the two vessels was opened and gas was rapidly evolved from the leaves. The inlet valve of the tube containing the leaf was then opened to allow a steady stream of air to flow through the tube and into the Hyamine solution. Equilibration of pressure was reached in about $20 \mathrm{~min}$. The flask containing the Hyamine was then sealed and shaken for a further $20 \mathrm{~min}$ to ensure complete absorption of ${ }^{14} \mathrm{CO}_{2}$.

Other soluble radioactive compounds were extracted from the leaves as described by Hatch \& Slack (1966). Samples of the chloroform extract remaining after extraction of hydrazones into $0.5 \mathrm{M}-\mathrm{Na}_{2} \mathrm{CO}_{3}$ were used to determine phaeophytin and hence chlorophyll (Vernon, 1960). The insoluble residue was washed with water and then suitable portions were collected on glass-fibre discs, dried, and counted to determine the radioactivity in starch. In the case of maize the remaining material was dried at $80^{\circ} \mathrm{C}$ and weighed.

Samples of all fractions were counted in a scintillation mixture containing $8 \%(w / v)$ naphthalene and $0.5 \%(w / v)$ 2,5 - diphenyloxazole in dioxane - toluene - ethanol (377:377:246, by vol.).

The proportions of radioactivity in individual compounds was determined by chromatography as previously described (Hatch \& Slack, 1966; Johnson \& Hatch, 1969).

Purification and degradation of compounds. Radioactive malate, aspartate and glycerate were purified by chromatography as described by Johnson \& Hatch (1969). Glycerate was degraded as described by Hatch \& Slack (1966). Radioactivity in the C-4 of aspartate was determined by treatment with aspartate decarboxylase (contained in glutamate decarboxylase provided by Sigma Chemical Co., St Louis, Mo., U.S.A.). Reaction mixtures containing $50 \mathrm{~mm}$-potassium acetate buffer, pH 5.0, 1 mM-L-aspartate, $0.1 \mathrm{mg}$ of pyridoxal phosphate/ $\mathrm{ml}$ and $5 \mathrm{mg}$ of the enzyme preparation were incubated for $5 \mathrm{~h}$ at $35^{\circ} \mathrm{C}$. Radioactivity appearing in $\mathrm{CO}_{2}$ was determined by counting the radioactivity of samples taken before and after this treatment. The radioactivity in the C-4 of malate was determined by treating samples of malate for $30 \mathrm{~min}$ at $30^{\circ} \mathrm{C}$ in reaction mixtures containing 0.1 unit of 'malic' enzyme, 2 units of alanine aminotransferase, 50 mM-tris-HCl buffer, pH 7.5, $3 \mathrm{~mm}$ $\mathrm{MnCl}_{2}, 5 \mathrm{~mm}-\mathrm{NADP}$ and $10 \mathrm{~mm}$-glutamate. After acidification with formic acid the radioactivity released as $\mathrm{CO}_{2}$ was determined as described above. Degradation procedures were verified by treating samples of [U-14 $\mathrm{C}$ - and $\left[4^{-14} \mathrm{C}\right]$-malate and -aspartate.

\section{RESULTS}

Labelling of $\mathrm{CO}_{2}$ and other intermediates in maize leaves. The pattern of labelling of intermediates from ${ }^{14} \mathrm{CO}_{2}$ in maize leaves was similar to that described for sugar cane (Kortschak, Hartt \& Burr, 1965; Hatch \& Slack, 1966). The $\mathrm{C}_{4}$ acids, malate plus aspartate, were labelled at a maximum rate from zero time whereas 3-phosphoglycerate, hexose 

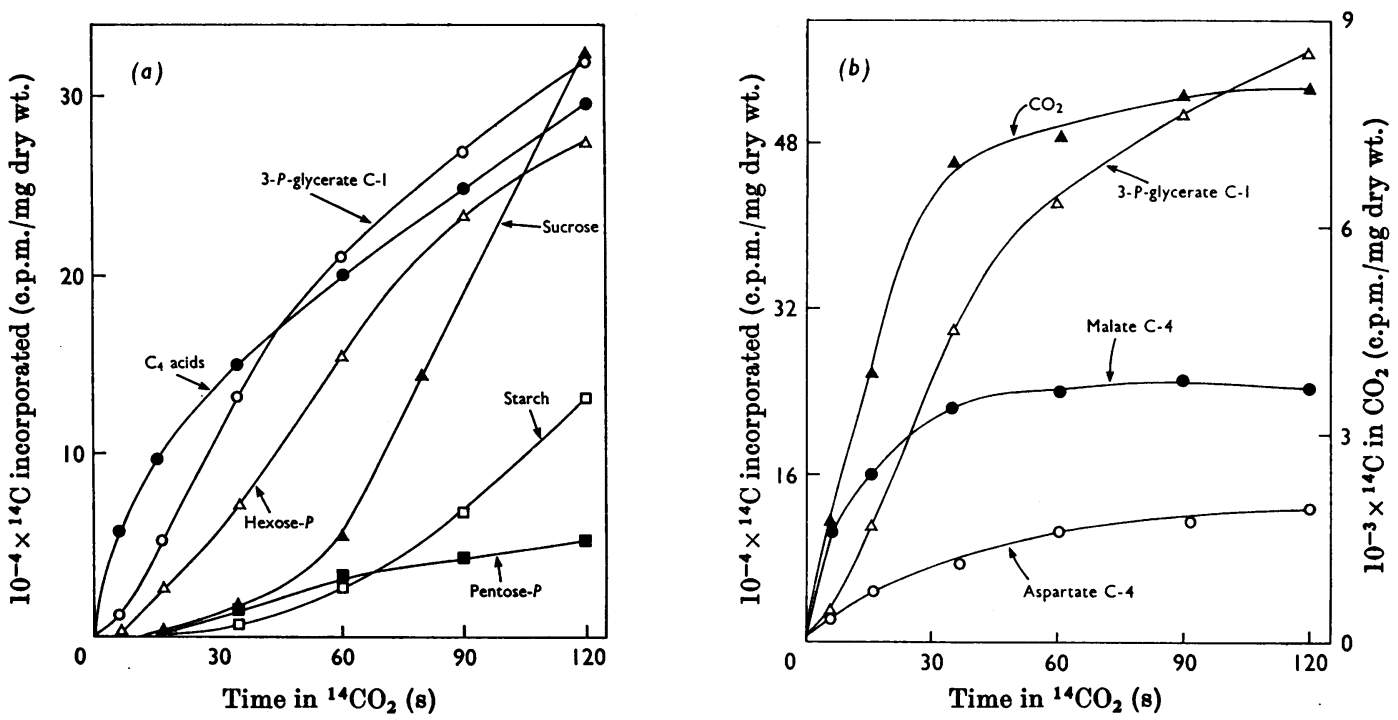

Fig. $1(a)$ and (b). Incorporation of radioactivity into compounds and specific carbon atoms of maize leaves exposed to ${ }^{14} \mathrm{CO}_{2}$. Experimental details are provided in the Methods section.

phosphates and pentose phosphates were rapidly labelled after increasing lag periods (Fig. la). The total radioactivity in the $\mathrm{C}_{4}$ acids continued to increase up to $120 \mathrm{~s}$. In contrast, the C-4 of malate was almost completely saturated with ${ }^{14} \mathrm{C}$ by $30 \mathrm{~s}$ whereas that of aspartate was saturated more slowly (Fig. 1b). The internal $\mathrm{CO}_{2}$ pool was small compared with the malate pool but the kinetics of its labelling closely followed those of the C-4 of malate. The maximum rate of labelling of the C-1 of 3-phosphoglycerate occurred after about $20 \mathrm{~s}$ by which time the $\mathrm{CO}_{2}$ pool was approaching saturation.

During a 'chase' with ${ }^{12} \mathrm{CO}_{2}$ malate lost radioactivity much more rapidly than aspartate (Fig. $2 a$ ). The most rapid loss of label from aspartate occurred after the major loss of label from malate. Likewise, the maximum rate of loss of label from 3-phosphoglycerate occurred when the loss from malate and aspartate was almost complete. Labelling of other compounds was in accordance with previous proposals for the operation of the $\mathrm{C}_{4}$ pathway (Hatch \& Slack, 1970a; Andrews et al. 1971). The results in Fig. $2 b$ confirm an earlier suggestion (Hatch \& Slack, 1966) that the radioactivity remaining in the $\mathrm{C}_{4}$ acids is due to label entering C-1, C-2 and C-3. In Fig. 2 radioactivity is expressed as \% of that present at the start of the 'chase' with ${ }^{12} \mathrm{CO}_{2}$ to simplify the comparison of the kinetics of loss of label. The C-4 of malate and aspartate were almost free of label by $90 \mathrm{~s}$ but the initial loss of label from the C.4 of malate was much more rapid. For instance after $10 \mathrm{~s}$ more than $50 \%$ of the label in the C-4 of malate was lost compared with about $10 \%$ for the C-4 of aspartate. The initial loss of label from $\mathrm{CO}_{2}$ proceeded at a rate intermediate between the rates for the C-4 of the $\mathrm{C}_{4}$ acids, consistent with it being derived from these carbons. Subsequently, the loss of label from $\mathrm{CO}_{2}$ was somewhat slower than from the C-4 of the $\mathrm{C}_{4}$ acids. Considering the size and turnover time of this pool (see Table 1) it might have been expected, ideally, to have followed more closely the kinetic behaviour of the C-4 of the $\mathrm{C}_{4}$ acids. The maximum rate of loss of label from the C-1 of 3-phosphoglycerate occurred after the major part of the label had been lost from the C-4 of $\mathrm{C}_{4}$ acids and $\mathrm{CO}_{2}$.

Labelling of $\mathrm{CO}_{2}$ and other intermediates in Amaranthus leaves. In most respects the pattern of labelling of intermediates during the exposure of Amaranthus leaves (Fig. $3 a$ ) to ${ }^{14} \mathrm{CO}_{2}$ was similar to that observed for maize. One difference was the marked labelling of alanine in Amaranthus, a feature that has been observed in Atriplex (Johnson \& Hatch, 1968). The rate of labelling of alanine closely followed that of C-1, C-2 and C-3 of the $\mathrm{C}_{4}$ acids. Also, in contrast with maize, more label appeared in aspartate than in malate and the maximum labelling of the C-4 of aspartate occurred at least as rapidly as the C-4 of malate (Fig. 3b). The approach to radioactive saturation of the $\mathrm{CO}_{2}$ pool closely followed that of the C-4 of the $\mathrm{C}_{4}$ acids. As with maize the C-1 of 3-phosphoglycerate reached a maximum rate of labelling only as the $\mathrm{CO}_{2}$ pool approached its maximum specific radioactivity. 

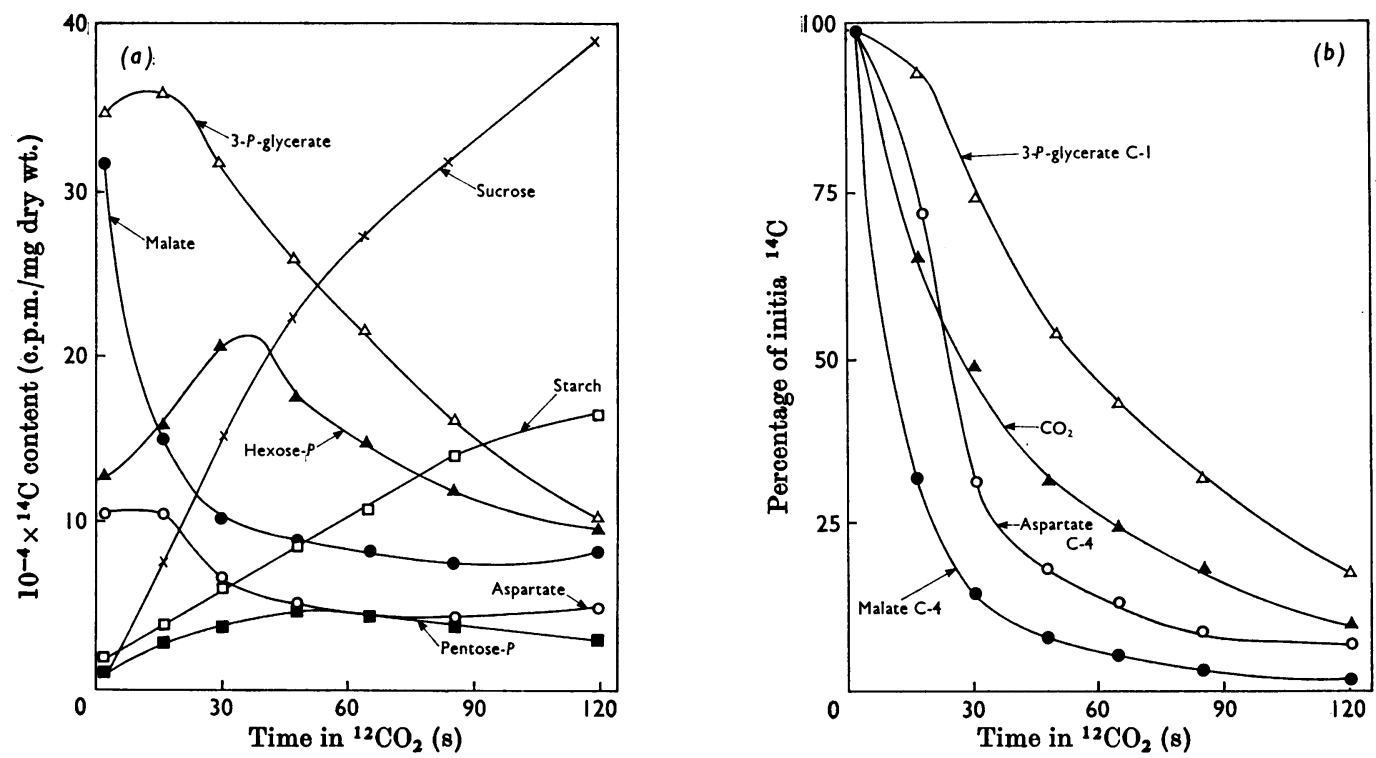

Fig. 2(a) and (b). Changes in radioaotivity in compounds and specific carbon atoms of maize leaves during a 'chase' in ${ }^{12} \mathrm{CO}_{2}$. At zero-time leaves were transferred to ${ }^{12} \mathrm{CO}_{2}$ after a period of $35 \mathrm{~s}$ in ${ }^{14} \mathrm{CO}_{2}$. Other details are provided in the Methods section.

Table 1. Size and concentration of $\mathrm{CO}_{2}, \mathrm{C}_{4}$ acid and 3-phosphoglycerate pools

Pool sizes were calculated as described in the text from the results in Fig. $1(a)$ and Fig. 3(a). Turnover times were calculated from the pool size and the observed rates of $\mathrm{CO}_{2}$ fixation in these experiments (5.5 and $6 \mu \mathrm{mol}$ of $\mathrm{CO}_{2} / \mathrm{min}$ per $\mathrm{mg}$ of chlorophyll for maize and Amaranthus, respectively). The turnover time for 3-phosphoglycerate was calculated on the assumption of a turnover rate twice that of the rate of $\mathrm{CO}_{2}$ fixation. This value was an underestimate since the C-1 of 3-phosphoglycerate had not reached maximum specific radioactivity. The basis for the calculation of concentrations is disoussed in the text.

Estimated concentration (mM)

Species

Maize

$\begin{array}{ll} & \mathrm{CO}_{2} \text { (dark) } \\ \mathrm{CO}_{2} \\ \text { Malate } \\ \text { Aspartate } \\ \text { 3-Phosphoglycerate } \\ \\ \\ \text { Amaranthus } \\ \mathrm{CO}_{2} \text { (dark) } \\ \mathrm{CO}_{2} \\ \text { Aspartate } \\ \text { Malate } \\ \text { 3-Phosphoglycerate }\end{array}$

In contrast with maize, with Amaranthus leaves label was lost more rapidly from aspartate than malate during a 'chase' in ${ }^{12} \mathrm{CO}_{2}$ (Fig. 4a). The pattern of appearance of this label in 3-phosphoglycerate, hexose phosphates, pentose phosphates and the photosynthetic end products was consistent
Turnover

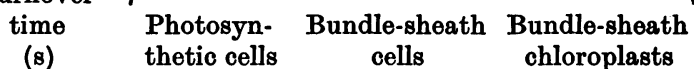

$\begin{aligned} & 0.007 \\ & 0.072 \\ & 0.97 \\ & 0.55 \\ &>2.4 \\ & \\ & 0.02 \\ & 0.23 \\ & 1.02 \\ & 0.76 \\ &>\mathbf{3 . 1}\end{aligned}$

0.8

13.5

$>\overline{18}$

0.017
0.17
2.4
1.4
$>6$

- 2.8

14

$>22$

$\begin{array}{ll}-0.8 & - \\ - & -6 \\ - & - \\ - & - \\ 1.9 & 4.5 \\ - & - \\ - & -\end{array}$

with the operation of the Calvin cycle as in the scheme proposed by Andrews et al. (1971). As with the time-course in ${ }^{14} \mathrm{CO}_{2}$ the change of label in alanine was similar to that observed for the sum of C-1, C-2 and C-3 of the $\mathrm{C}_{4}$ acids.

With Amaranthus leaves the initial rate of loss 

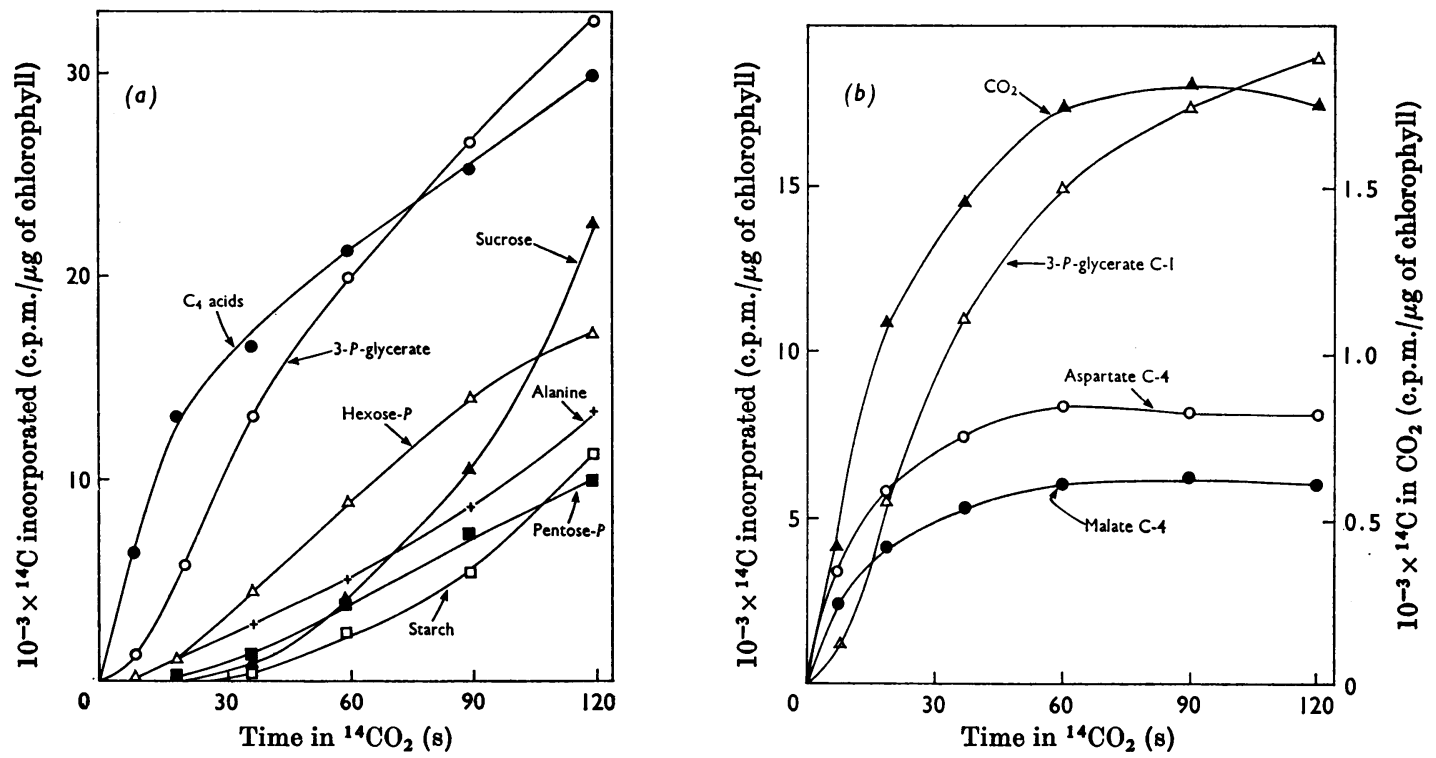

Fig. 3(a) and (b). Incorporation of radioactivity into compounds and specific carbons of Amaranthus leaves exposed to ${ }^{14} \mathrm{CO}_{2}$. Experimental details are given in the Methods section.

of label from the C.4 of aspartate during the 'chase' in ${ }^{12} \mathrm{CO}_{2}$ was much faster than that from the C-4 of malate (Fig. $4 b$ ). The rate of loss of label from $\mathrm{CO}_{2}$ was intermediate between that of the C-4 of aspartate and of malate. As with maize the maximum rate of loss of label from the C-1 of 3. phosphoglycerate occurred only after the majority of the label had moved from the C-4 of the $\mathrm{C}_{4}$ acids and the $\mathrm{CO}_{2}$ pool.

Pool sizes, concentrations and turnover times. From the specific radioactivity of the ${ }^{14} \mathrm{CO}_{2}$ supplied and the amount of radioactivity in specific carbons when they were saturated with ${ }^{14} \mathrm{C}$ (Figs. $1 b$ and $3 b$ ), it was possible to calculate the pool size of $\mathrm{CO}_{2}, \mathrm{C}_{4}$ acids and 3-phosphoglycerate (Table 1). In separate experiments the size of the $\mathrm{CO}_{2}$ pool in leaves placed in the dark was also determined. Leaves were allowed to establish a steady rate of photosynthesis by illuminating them at $8000 \mathrm{ft}$ candles for $45 \mathrm{~min}$ and then placing them in the dark. After $35 \mathrm{~s}^{14} \mathrm{CO}_{2}$ was provided and individual leaves were removed for analysis at intervals thereafter. The maximum labelling of $\mathrm{CO}_{2}$ in both maize and Amaranthus leaves was found in the first leaf samples, taken $30 \mathrm{~s}$ after providing ${ }^{14} \mathrm{CO}_{2}$, and it remained constant up to $120 \mathrm{~s}$. During this period any closure of stomata caused by placing the leaves in the dark would be insignificant (R. W. Downes, unpublished work). With both species the rate of fixation into $\mathrm{C}_{4}$ acids was initially about $12 \%$ of the rate in the light but declined to $1-1.5 \%$ by $120 \mathrm{~s}$. Fixed label was only detected in oxaloacetate, malate and aspartate. Thus until about $2 \mathrm{~min}$ after illumination $\mathrm{C}_{4}$ acid synthesis is enhanced compared with the steady rate in the dark. Some of the $\mathrm{CO}_{2}$ found in leaves in the dark may have been derived from acids formed during this period of enhanced synthesis. Nevertheless, the total $\mathrm{CO}_{2}$ pool in the dark was only about $10 \%$ of that in the light.

The pools of $\mathrm{C}_{4}$ acids and 3-phosphoglycerate were relatively large compared with the $\mathrm{CO}_{2}$ pool (Table 1). The values for 3-phosphoglycerate were based on the radioactivity in C-1 at 120s (Figs. $1 b$ and $3 b)$. Approximations made by extending the curves for the C-1 of 3-phosphoglycerate indicated that it was probably about $80 \%$ saturated at this time. From the turnover time of the $\mathrm{C}_{4}$ acid pools it was possible to calculate the expected half-time for loss of radioactivity from the C-4 in a 'chase' experiment, assuming this loss obeyed first order kinetics. The calculated values were $9 \mathrm{~s}$ for the C-4 of malate in maize and $10 \mathrm{~s}$ for the C-4 of aspartate in Amaranthus. Observed values were about 10s (Fig. 2b) and 15s (Fig. 4b), respectively.

Enzyme studies have been interpreted to indicate that $\mathrm{CO}_{2}$ is released in the bundle-sheath chloroplasts of maize and either the bundle-sheath cells or chloroplasts of Amaranthus (Andrews et al. 1971). It was therefore useful to calculate the concentration 

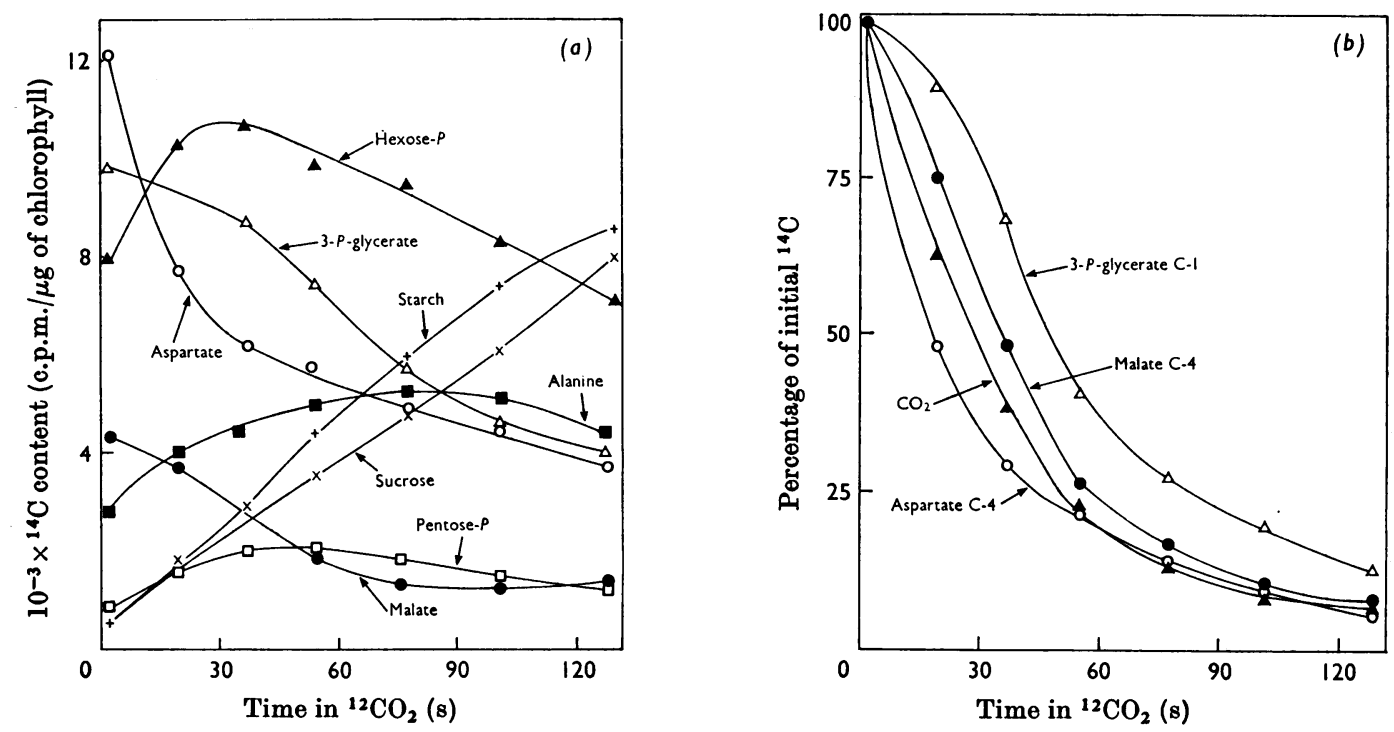

Fig. 4(a) and (b). Changes in radioactivity in compounds and specific carbons of Amaranthus leaves during a 'chase' in ${ }^{12} \mathrm{CO}_{2}$. At zero-time leaves were transferred to ${ }^{12} \mathrm{CO}_{2}$ after a period of $35 \mathrm{~s}$ in ${ }^{14} \mathrm{CO}_{2}$. Further experimental details are provided in the Methods section.

of $\mathrm{CO}_{2}$ by using the assumption that it is confined largely to one or other of these compartments. Estimates of the proportion of the total leaf volume occupied by the bundle-sheath cells and chloroplasts were made from light micrographs of leaf cross sections. For this calculation it was assumed that both cells and chloroplasts approximated to spheres. The values obtained were $10 \%$ for the bundle-sheath cells and $5 \%$ for the bundlesheath chloroplasts of maize and 12 and $5 \%$ respectively for Amaranthus. No correction was made for vacuolar volumes. The concentrations quoted in Table 1 assume that all the $\mathrm{CO}_{2}$ detected was located in the respective compartments indicated.

Assuming that the $\mathrm{CO}_{2}$ in leaves placed in the dark provides a maximum estimate of the size of non-specific pools then at least $90 \%$ of the $\mathrm{CO}_{2}$ in illuminated leaves could represent a specific pool involved in photosynthesis. Alternatively, by using simple physical data (Umbreit, Burris \& Stauffer, 1959), estimates can be made of the amounts of $\mathrm{CO}_{2}$ gas and of $\left(\mathrm{CO}_{2}+\mathrm{HCO}_{3}{ }^{-}\right) / \mathrm{g}$ of leaf in equilibrium with atmospheric $\mathrm{CO}_{2}$. The amount of $\mathrm{CO}_{2}$ gas in the liquid phase would be about $6 \mathrm{nmol} / \mathrm{g}$ fresh wt. Assuming a cytoplasmic $\mathrm{pH}$ of 7.0 , a cytoplasmic volume of $20 \%$ of the leaf volume, and equilibration between $\mathrm{CO}_{2}$ and $\mathrm{HCO}_{3}{ }^{-}$, the concentration of $\mathrm{CO}_{2}$ plus $\mathrm{HCO}_{3}^{-}$would be about $15 \mathrm{nmol} / \mathrm{g}$ fresh wt. It should be noted that during steady-state photosynthesis the concentration of
$\mathrm{CO}_{2}$ in the freely accessible liquid space of the cell would be less than that at diffusion equilibrium.

\section{DISCUSSION}

It has been proposed that the unique reactions of the $\mathrm{C}_{4}$-pathway, those leading to the release of $\mathrm{CO}_{2}$ from $\mathrm{C}_{4}$ acids, have the main function of concentrating $\mathrm{CO}_{2}$ for fixation by ribulose diphosphate carboxylase (Andrews et al. 1971; Hatch, 1971). Even with the liquid phase concentration of $\mathrm{CO}_{2}$ in diffusion equilibrium with atmospheric $\mathrm{CO}_{2}$, the turnover for the reaction catalysed by ribulose diphosphate carboxylase would be quite inadequate to account for its operation as an integral reaction of photosynthesis (Hatch \& Slack, 1970b). The equilibrium concentration of $\mathrm{CO}_{2}$ in solution would be about $7 \mu \mathrm{M}$ but the $K_{m}$ of ribulose diphosphate carboxylase for $\mathrm{CO}_{2}$ is at least 50 times this concentration (Cooper, Filmer, Wishnick \& Lane, 1969; Andrews $\&$ Hatch, 1971). In contrast, even with $\mathrm{CO}_{2}$ concentrations well below $7 \mu \mathrm{M}$ the activity and $K_{m}$ of phosphoenolpyruvate carboxylase for $\mathrm{CO}_{2}$ in $\mathrm{C}_{4}$-pathway species would permit a turnover sufficient to account for its operation in the primary $\mathrm{CO}_{2}$-fixing process (Hatch, 1971).

The present studies provide evidence that, in the light, the size of the leaf $\mathrm{CO}_{2}$ pool in $\mathrm{C}_{4}$-pathway species is much higher than would be expected from simple diffusion of $\mathrm{CO}_{2}$ into the liquid phases of 
the tissue. The most direct evidence for this was that the size of the pool developed during photosynthesis was about ten times greater than that found in leaves placed in the dark. Calculations of the maximum concentrations of $\mathrm{CO}_{2}$ gas or $\mathrm{CO}_{2}$ plus bicarbonate likely to occur in leaves equilibrated in air with $\mathrm{CO}_{2}$ supported this conclusion. Other calculations (Table 1) showed that if the $\mathrm{CO}_{2}$ pool in illuminated leaves was largely confined to the bundle-sheath cells or bundle-sheath chloroplasts its concentration would be about $1 \mathrm{mM}$ or more. Such concentrations would sustain nearmaximum operation of ribulose diphosphate carboxylase. Assuming the operation of a process for concentrating $\mathrm{CO}_{2}$ in the bundle-sheath cells or chloroplasts it appears likely that a permeability barrier may exist to restrict dissipation of this $\mathrm{CO}_{2}$. As a consequence, movement of atmospheric $\mathrm{CO}_{2}$ into the bundle-sheath chloroplasts would also be restricted. This would accord with the observations that most, if not all, of the label entering the C-1 of 3-phosphoglycerate from ${ }^{14} \mathrm{CO}_{2}$ is derived from the C.4 of $\mathrm{C}_{4}$ acids (Johnson \& Hatch, 1969) and that the rate of transfer of label from the C-4 to 3-phosphoglycerate is not decreased by increasing the ${ }^{12} \mathrm{CO}_{2}$ concentration (Hatch \& Slack, 1966).

The inferences drawn above concerning the nature of the $\mathrm{CO}_{2}$ pool in illuminated leaves were supported by the kinetics of labelling of $\mathrm{CO}_{2}$. The results of these studies are consistent with the idea that the pools in both maize and Amaranthus are at least largely derived from the C-4 of a $\mathrm{C}_{4}$ acid and are the precursor of the C-1 of 3-phosphoglycerate. These kinetics were not those expected if the $\mathrm{CO}_{2}$ pool was derived directly from atmospheric $\mathrm{CO}_{2}$ to serve either phosphoenolpyruvate carboxylase or ribulose diphosphate carboxylase. With this origin, and with the size and consequent turnover time of this pool, its half-time for saturation during a pulse in ${ }^{14} \mathrm{CO}_{2}$, and for depletion of radioactivity during a chase in ${ }^{12} \mathrm{CO}_{2}$, should have been about $2 \mathrm{~s}$ or less. In contrast, the observed half-times were between 15 and $20 \mathrm{~s}$.

As indicated in the introduction the $\mathbf{C}_{\mathbf{4}}$-pathway species containing high 'malic' enzyme activity probably transport malate to the bundle-sheath chloroplasts to provide $\mathrm{CO}_{2}$. An associated character of these particular species is the deficiency of both grana and photosystem 2 activity in the bundle sheath chloroplasts (Downton, Berry \& Tregunna, 1970; Woo et al. 1970; Anderson, Boardman \& Spencer, 1971). Significantly the operation of 'malic' enzyme to release $\mathrm{CO}_{2}$ would also yield NADPH. A second group of $\mathrm{C}_{4}$-pathway species were found to contain little 'malic' enzyme but high aminotransferase activities and were assumed to transport aspartate instead of malate (Andrews et al. 1971). The conclusion that the $\mathbf{C}_{4}$ acid donating $\mathrm{CO}_{2}$ may vary in different species received support from the present studies. Chen et al. (1971) deduced from earlier findings (Hatch \& Slack, 1966) that the gross label in malate declined more rapidly than the label in aspartate during a 'chase' experiment with sugar cane leaves and observed the reverse with bermuda grass. They related these differences to differences in 'malic' enzyme activity and suggested that the labelling behaviour may be indicative of the $\mathrm{C}_{4}$ acid functioning as the primary source of the C-1 of 3-phosphoglycerate. In the present studies maize, a species with high 'malic' enzyme activity, behaved like sugar cane. In contrast, in Amaranthus, a species with low 'malic' enzyme activity, label was lost more rapidly from aspartate, as was the case with bermuda grass. During the present studies the labelling changes in the specific carbon (C-4) involved in this transfer were also examined, thereby eliminating the complicating effect of label entering C-1, C-2 and C-3. Generally speaking, the changes observed in the C.4 label qualitatively followed those observed in the gross label of the $\mathrm{C}_{4}$ acids in spite of the substantial influence of label entering C-1, C-2 and C-3.

The results discussed above are consistent with the scheme for the $\mathbf{C}_{4}$-pathway formulated earlier (Andrews et al. 1971; Hatch, 1971). Further it is notable that alanine was only slightly labelled in maize but markedly labelled in Amaranthus. The labelling of alanine closely resembled that of C-1, C-2 and C-3 of the $\mathrm{C}_{4}$ acids. According to the scheme, alanine functions as an intermediate in the regeneration of phosphoenolpyruvate, being derived in turn from the C-1, C-2 and C-3 of aspartate. In relation to this scheme it should also be emphasized that at present there is no evidence for the exclusive operation of either malate or aspartate as a $\mathrm{CO}_{2}$ donor in any species. Enzyme results suggest the predominance of one route or the other in many species (Downton, 1970; Andrews et al. 1971; Chen et al. 1971). However, malate and aspartate may contribute about equally in Gomphrena (Andrews et al. 1971). With the species examined during the present studies label was rapidly lost from the C-4 of both malate and aspartate during 'chase' studies. However, the kinetics of loss from the $\mathrm{C}_{4}$ acid assumed to be in the side pool was quite consistent with label being transferred to the donor $\mathrm{C}_{4}$ acid via oxaloacetate. It is not possible to say whether all the loss of label from the $\mathrm{C}_{4}$ acids in the side pool occurred in this manner.

The technical assistance of Miss Remi Rochino is gratefully acknowledged. 


\section{REFERENCES}

Anderson, J. M., Boardman, N. K. \& Spencer, D. (1971). Biochim. biophys. Acta (in the Press).

Andrews, T. J. \& Hatoh, M. D. (1971). Phytochemistry, $10,9$.

Andrews, T. J., Johnson, H. S., Slack, C. R. \& Hatch, M. D. (1971). Phytochemistry (in the Press).

Berry, J. A., Downton, W. J. S. \& Tregunna, E. B. (1970). Can. J. Bot. 48, 777.

Bjorkman, O. \& Gauhl, E. (1969). Planta, 88, 197.

Chen, T. M., Brown, R. H. \& Black, C. C. (1971). Pl. Physiol., Lancaster, 47, 199.

Cooper, T. G., Filmer, D., Wishnick, M. \& Lane, M. D. (1969). J. biol. Chem. 244, 1081.

Downton, W. J. S. (1970). Can.J. Bot.48, 1795.

Downton, W. J. S., Berry, J. A. \& Tregunna, E. F. (1970). Z. PflPhysiol. 63, 194.

Edwards, G. E. \& Black, C. C. (1971). In Photosynthesis and Photorespiration, p. 153. Ed. by Hatch, M. D., Osmond, C. B. \& Slatyer, R. O. New York: Interscience Publishers Inc.

Edwards, G. E., Lee, S. S., Chen, T. M. \& Black, C. C. (1970). Biochem. biophys. Res. Commun. 39, 389.

Hatch, M. D. (1971). In Photosynthesis and Photorespiration, p. 139. Ed. by Hatch, M. D., Osmond, C. B. \& Slatyer, R. O. New York: Interscience Publishers Inc.
Hatch, M. D., Osmond, C. B. \& Slatyer, R. O. (Ed.) (1971). Photosynthesis and Photorespiration. New York: Interscience Publishers Inc.

Hatch, M. D. \& Slack, C. R. (1966). Biochem. J. 101, 103.

Hatch, M. D. \& Slack, C. R. (1968). Biochem. J. 106, 141.

Hatch, M. D. \& Slack, C. R. (1970a). In Progress in Phytochemistry, vol. 2, p. 35. Ed. by Reinhold, L. \& Liwschitz, Y. London: Interscience.

Hatch, M. D. \& Slack, C. R. (1970b). A. Rev. Pl. Physiol. 21, 141.

Johnson, H. S. \& Hatch, M. D. (1968). Phytochemistry, $7,375$.

Johnson, H. S. \& Hatch, M. D. (1969). Biochem. J. 114, 127.

Johnson, H. S. \& Hatch, M. D. (1970). Biochem. J. 119, 273.

Kortschak, H. P., Hartt, C. E. \& Burr, G. O. (1965). Pl. Physiol., Lancaster, 40, 209.

Slack, C. R. \& Hatch, M. D. (1967). Biochem. J. 103, 660.

Slack, C. R., Hatch, M. D. \& Goodchild, D. J. (1969). Biochem. J. 114, 489.

Umbreit, W. W., Burris, R. H. \& Stauffer, J. F. (1959). In Manometric Techniques, pp. 18-27, Minneapolis: Burgess Publishing Co.

Vernon, L. P. (1960). Analyt. Chem. 32, 1144.

Woo, K. C., Anderson, J. M., Boardman, N. K., Downton, W. J. S., Osmond, C. B. \& Thorne, S. W. (1970). Proc. natn. Acad. Sci. U.S.A. 67, 1825. 